\title{
Duration of Treatment for "Disease Arrest" of Non-Lepromatous cases and Relapse Rate in these Patients
}

\author{
V. EKAMBARAM \\ Elep Dharma puriand Damien Foundation in India, Madras
}

\begin{abstract}
This is a study of 1879 patients declared disease arrested in the Elep Leprosy Project, Dharmapuri. The study analyses the duration of treatment needed for rendering a patient disease inactive and disease arrested and the number of relapses occurring among these cases. The relapses have been analysed with references to the maintenance and total treatment the patients had before relapse, and the periodicity of relapse, after being declared disease arrested with a view to determining the minimum treatment needed for disease arrest, the surveillance needed after discharge from treatment, etc.
\end{abstract}

\section{Introduction}

When a person diagnosed of suffering from leprosy gets over the initial psychological shock, he then asks his physician whether the disease is curable and if so the duration of treatment needed. Hence the main objective of health education about leprosy is not only to assure the patients and the public that leprosy is curable but also to state the approximate duration of treatment needed. Though we always tell the public that leprosy is curable, still, we fight shy of using the word "cured" but use various expressions to denote the same viz., released from control, disease arrested and lesions resolved. But among the above, the most preferable is disease arrested and so this expression is used in this paper to denote cure. Since we want to give as accurate an answer as possible as to the period of treatment needed for disease arrest, we decided to find out from a study of patients declared disease arrested the period of treatment needed for rendering a non-lepromatous patient disease inactive, the maintenance therapy needed thereafter till they are declared disease arrested, and the total duration of treatment for being declared disease arrested, with reference to the number of patches, involvement of nerves and also the 
regularity of treatment. We have also studied the relapse rate and the relationship of relapse to such variables as duration of maintenance therapy, regularity of treatment and number of patches in these patients.

\section{Materials and Methods}

This paper is based on the findings in the patients declared "disease arrested" in the Elep Leprosy Control Project, Dharmapuri.

\section{SELEC TION OF PATIENTS FOR STUDY}

All the non-lepromatous patients (only 'T' or 'M.A.' cases) declared 'disease arrested" in 18 subcentres, started on therapy between 1968 and 1974 and declared "disease arrested" till the end of 1977 have been analysed in this paper.

Drug for therapy in all these cases was D.D.S. given orally (400 mg a week). Criteria for declaring "disease arrested" are those laid down in the operational guide of the Government of India (by a committee consisting of senior leprologists of India).

The criteria are as follows: 1. For non-lepromatous 'T' or 'M.A.' (1) one and a half years after the patient is declared "disease inactive" during which period treatment is continued in full dosage.

Treatment was by medical officers at monthly clinics at various subcentres.

\section{ASSESSMENT OF CASES}

Periodical assessment of cases was done every year for declaring a patient "disease inactive" or disease arrested. Quite a few patients became irregular or were absent for treatment after being declared inactive. In such cases, the condition of the patient at the end of the specified period after being declared "disease inactive", (one and a half years) was taken as a guide to declare him "disease arrested" and not the actual period of treatment taken. After being declared disease arrested and discharged from treatment, patients were examined periodically by the medical officer at the clinics for 2 years and thereafter, the para-medical worker kept them under observation by home visits.

\section{DEFINITIONS}

Few patches

Multiple patches: more than 2 but less than 5

Nerves involved : either one or more nerves

$\left\{\begin{array}{l}\text { at the time } \\ \text { of start of } \\ \text { therapy }\end{array}\right.$

Disease inactive is the stage at which no signs of activity of the disease are present.

Disease arrest is synonymous with release from control.

Maintenance therapy is treatment given after being declared "disease inactive" and bef ore being disease arrested. 
TABLE 1

\begin{tabular}{lccc}
\hline $\begin{array}{l}\text { Total non-lepromatous } \\
\text { patients declared } \\
\text { "disease arrested" } \\
\text { till end of } 1977\end{array}$ & $\begin{array}{c}\text { No. of these } \\
\text { studied in } \\
1978\end{array}$ & $\begin{array}{c}\text { No. among } \\
\text { these with } \\
\text { few patches }\end{array}$ & $\begin{array}{c}\text { Patients with } \\
\text { multiple } \\
\text { patches }\end{array}$ \\
\hline 4990 & 1879 & $\begin{array}{c}1441 \\
\text { or } \\
76.6 \%\end{array}$ & $\begin{array}{c}438 \text { or } 23.4 \% \\
\text { of the total } \\
\text { declared "disease } \\
\text { arrested" }\end{array}$ \\
\hline
\end{tabular}

\section{FINDING OF STUDY}

The total number of patients declared "disease arrested" ('T' and 'M.A.' cases) is given in Table 1.

\section{COMMENTS}

Out of the total cases declared "disease arrested" the majority $76.6 \%$ are those with few patches, whereas only $23.4 \%$ are those with multiple patches. It is of interest to state that among patients with multiple or few patches, if the nerves are involved, only few patients have become disease arrested.

Out of 1441 patients with few patches, 303 or $21 \%$ with nerve involvement have become disease arrested. Similarly, 177 out of 438 patients or $41 \%$ of patients with multiple patches and with nerve involvement have become disease arrested.

\section{Duration of Treatment for becoming "Disease Inactive" (Sign Free).}

As regards the period of treatment needed for a non-lepromatous case to become disease inactive, it is found that: (a) those with few patches need an average of 179 weeks of treatment; (b) those with multiple patches need an average of 200 weeks of treatment.

Even among these, it is seen that those with nerve involvement among patients with few patches need 181 weeks of treatment.

Those with nerve involvement among patients with multiple patches need 205 weeks of treatment.

So, involvement of nerve prolongs the duration of treatment needed for disease arrest.

\section{Maintenance Therapy}

It is of interest to study the duration of maintenance therapy the patients needed before being declared "disease arrested". (a) In total, a nonlepromatous case needs 106 weeks (a patient with few patches needs only 98 weeks whereas one with multiple patches needs 114 weeks of maintenance therapy. 


\section{Total Duration of Treatment for being Declared "Disease Arrested"}

(a) Among those with few patches with or without nerve involvement duration of treatment is 277 weeks and (b) among those with multiple patches with or without nerve involvement 319 weeks.

On an average, a non-lepromatous case needs about 296 weeks for becoming "disease arrested".

\section{COMMENTS}

It is seen that an average of 6 years of treatment is needed for a nonlepromatous case for becoming disease arrested.

\section{Regularity of Treatment with Reference to "Disease Arrest"}

A study has also been made to find out the relationship of regularity for treatment with the number of those declared "disease arrested" about which information is given in Table 2 .

\section{TABLE 2}

\begin{tabular}{|c|c|c|c|}
\hline \multirow[b]{2}{*}{$\begin{array}{l}\text { Total no. of } \\
\text { patients declared } \\
\text { "disease arrested" } \\
\text { in non-lepromatous } \\
\text { cases }\end{array}$} & \multicolumn{3}{|c|}{ Declared disease arrested among } \\
\hline & $\begin{array}{l}\text { Those who took } \\
\text { very regular } \\
\text { treatment i.e., } \\
\text { above } 50 \% \text { of } \\
\text { the total } \\
\text { treatment }\end{array}$ & $\begin{array}{l}\text { Irregular } \\
\text { between } 25 \% \\
\text { to } 50 \% \text { of } \\
\text { the total } \\
\text { treatment }\end{array}$ & $\begin{array}{l}\text { Who were grossly } \\
\text { irregular i.e., } \\
\text { treatment below } \\
25 \% \text { of the total } \\
\text { treatment or } \\
\text { absent. }\end{array}$ \\
\hline $\begin{array}{l}\text { Adult: } 1637 \\
\text { ChildrenL } 242 \\
\text { Total: } 1879\end{array}$ & 1185 & 355 & 339 \\
\hline
\end{tabular}

\section{COMMENTS}

In general regularity of treatment has been found to help in "disease arrest" since the majority of patients declared "disease arrested" are those who have taken treatment regularly whereas among those that were irregular or absent, only a minority became "disease arrested".

\section{Relapse Rate Among Patients}

The total number of patients relapsed among the "disease arrested" is 34 consisting of 31 adults and 3 children.

The relationship of relapse with the number of lesions is given in Table 3 .

\section{COMMENTS}

There has been in total a relapse rate of $1.8 \%$ in the non-lepromatous cases released from control as "disease arrested". The relapse rate among adults is 
TABLE 3

\begin{tabular}{|c|c|c|c|c|c|}
\hline \multicolumn{4}{|c|}{ Cases relapsed up to 1978} & \multirow{2}{*}{\multicolumn{2}{|c|}{$\begin{array}{l}\text { No. of cases relapsed according to } \\
\text { no. of patches in non-lepromatous cases }\end{array}$}} \\
\hline 18 & Adults & Children & Total & & \\
\hline & & & & $\begin{array}{l}\text { Those with few } \\
\text { Patches }\end{array}$ & $\begin{array}{l}\text { Those with } \\
\text { Multiple Patches }\end{array}$ \\
\hline & 31 & 3 & 34 & 23 & 11 \\
\hline
\end{tabular}

$1.9 \%$ and among children slightly lower i.e., $1.2 \%$.

Analysing it further, it is seen that among the ' $N$ ' cases, with few patches the relapse rate is $1.6 \%$ whereas the relapse rate in those with multiple patches is higher i.e., $2.5 \%$.

Hence patients with multiple patches are at greater risk of relapse of the disease.

\section{Time Factor in Relapse}

A study has also been made to determine the period of time elapsing between being declared "disease arrested" and relapse, the findings of which are presented in Table 4.

TABLE 4

No. of cases

relapsed
Time interval between being declared "disease arrested" and relapse.

\begin{tabular}{ccccccc} 
& $\begin{array}{c}\text { After } \\
1 \mathrm{y}\end{array}$ & $\begin{array}{c}\text { After } \\
2 \mathrm{y}\end{array}$ & $\begin{array}{c}\text { After } \\
3 \mathrm{y}\end{array}$ & $\begin{array}{c}\text { After } \\
4 \mathrm{y}\end{array}$ & $\begin{array}{c}\text { After } \\
5 \mathrm{y}\end{array}$ & $\begin{array}{c}\text { After } \\
6 \mathrm{y}\end{array}$ \\
\hline 34 & 4 & 15 & 6 & 5 & 3 & 1 \\
\hline
\end{tabular}

\section{COMMENTS}

The maximum number of relapses have occurred in the first 2 years after discharge. Later on, there is a steady decline in the number of relapses. So, it is imperative that patients discharged from treatment should be under observation for at least 3 years after discharge from treatment.

It is also of interest to study the relationship between the duration of maintenance therapy and number of relapses in Table 5.

NOTE

Though the total patients declared "disease arrested" are 34, only 22 among them were regular for treatment (maintenance therapy) after being declared "disease inactive" for whom the duration of maintenance therapy with reference to relapse is presented in the Table 5. 
TABLE 5

Relationship between maintenance therapy and release

\begin{tabular}{llcccccc}
\hline $\begin{array}{l}\text { Total } \\
\text { no. of } \\
\text { relapsed }\end{array}$ & $\begin{array}{l}\text { No. of } \\
\text { patients } \\
\text { relapsed } \\
\text { studied with } \\
\text { reference to } \\
\text { maintenance } \\
\text { therapy }\end{array}$ & $\begin{array}{l}1 \frac{1}{2} \mathrm{yr} \\
\text { the patients declared disease arrested and } \\
\text { who have relapsed }\end{array}$ & $2 \mathrm{yr}$ & $2 \frac{1}{2} \mathrm{yr}$ & $3 \mathrm{yr}$ & $3 \frac{1}{2} \mathrm{yr}$ & $4 \mathrm{yr}$ \\
34 & 22 & 14 & 4 & 2 & 2 & - & - \\
\hline
\end{tabular}

\section{COMMENTS}

It is seen that the maximum relapses have occurred in those who had a maintenance therapy up to 2 years and the relapses reduce as the duration of maintenance therapy increases.

\section{Certain Interesting Features about the Relapsed Cases}

Among the 34 relapsed cases, 8 (only adults) have changed type, 3 to B.L. and 5 to B.T. It is gratifying to note that none of the child cases, who have relapsed changed type to 'B' or 'B.L'.

\section{Conclusion}

From the findings of this study in non-lepromatous cases, it is evident that patients with multiple lesions and involvement of nerves need longer treatment for disease arrest since they have greater likelihood of relapse. Also the relapses are more with shorter periods of maintenance therapy. Patients declared disease arrested need to be under surveillance for at least 3 years after discharge from treatment.

A non-lepromatous patient needs an average of 6 years of therapy to become disease arrested.

\section{References}

Parikh, A. C., Chulawala, R. G. and Ganapati, R. (1973). Criteria of discharge of leprosy patients from control. Lepr. India 45, 206.

Vellut, C., Lechat, M. F. and Misson, C. B. (1979). Maintenance therapy in non-lepromatous leprosy. Paper XI, 281, Eleventh International Leprosy Congress, Mexico, November 1978. Int. J. Lep. (1979), 47 (suppl.), 432. 